\title{
STUDY ON PLA/PA11 BIO-BASED TOUGHENING MELT-BLOWN NONWOVENS
}

\author{
Feichao Zhu, Bin Yu, Juanjuan Su, Jian Han \\ a.Silk Institute, College of Materials and Textiles; \\ b.Zhejiang Provincial Key Laboratory of Industrial Textile Materials and Manufacturing Technology, Zhejiang Sci-Tech University, Hangzhou 310018, China; \\ Corresponding author e-mail: hanjian8@zstu.edu.cn
}

\begin{abstract}
:
With aim to improve the mechanical and thermal properties of poly (lactic acid) (PLA) melt-blown nonwovens (MBs), polyamide 11 (PA11) was melt blended with PLA at the weight proportions of PLA/PA11 (95/5, 90/10, 85/15, 80/20), and the corresponding PLA/PA11 MBs were also manufactured. The crystallization, thermal and rheological behaviors of PLA/PA11 blends were investigated. PLA/PA11 MBs were also characterized by morphology and mechanical properties. The results indicated that PA11, as globular dispersed phases, formed confined crystals and could improve the thermal stability of PLA matrix. The viscosity of PLA/PA11 blends was slightly increased but the rheological behaviors of "shear-thinning" kept unchanged in comparison with PLA. The average diameter of PLA/PA11 MB fibers was slightly increased, whereas the toughness of PLA/PA11 MBs including the strength and elongation were efficiently enhanced compared with those of PLA MBs.
\end{abstract}

\section{Keywords:}

melt-blown nonwovens; poly (lactic acid); polyamide 11; toughening; thermal; rheological behaviors

\section{Introduction}

Melt-blown (MB) technology is a simple and industrialized one-step process for producing superfine fibers (average diameter $<5 \mu \mathrm{m}$ ). MB nonwovens have tremendous potentials and applications in areas of filtration, adsorption, medical, and health owing to their porous and fluffy structures [13]. However, most of the raw materials for MB nonwovens are petroleum-based polymers, such as polypropylene (PP) and polyethylene glycol terephthalate (PET). These petroleum-based and nondegradable MB nonwovens would inevitably increase the energy burden and bring some serious environmental problems in the near future. Bio-based MB nonwovens with excellent comprehensive properties have attracted more attentions.

Poly (lactic acid) (PLA) is the most well-known bio-based and biodegradable polymer which has been widely researched and applied in many fields [4-6], and PLA MB nonwovens also show a huge commercial market prospect. However, because of the inherent drawbacks of PLA, such as brittleness, low crystallization rate and thermal stability, the comprehensive performance of PLA MB nonwovens is also limited. Many strategies have been effectively employed to improve the toughness properties of PLA, among which polymer blending is an economical and practical approach to realize the toughness of PLA; moreover, it is also easy to be industrialized. Within PLA binary polymer blends, many bio-based flexible or elastomeric polymers, such as poly (butylene adipate-coterephthalate) (PBAT) [7], poly (ethylene glycol) (PEG) [8], poly (butylene succinate) (PBS) [9], polycaprolactone (PCL) [10], and some block or graft polymers [11-12], were adopted to obtain toughened PLA-based materials.
Polyamide 11 (PA11) is a $100 \%$ bio-based polymer whose monomer derives from castor oil. PA11 displays superior toughness and high thermal stability but low processing temperatures (crystalline melting temperature: $180-190^{\circ} \mathrm{C}$, much lower than PA6 and PA66) [13-15]. A few studies on PLA/ PA11 binary entire bio-based system were studied [16-17]; however, most of the researches on PLA/PA11 blends were in toughening film or injection modeling, and no study was focused on superfine fiber or MB nonwovens.

The purpose of the current study was to investigate the crystallization, thermal, and rheological behaviors of PLA/PA11 blends and then to obtain the corresponding toughened PLA/ PA11 MB nonwovens. The structure and properties of PLA/ PA11 MB nonwovens including morphology, fiber diameter, and mechanical properties were also investigated in detail.

\section{Experimental}

\subsection{Materials}

PLA (grade 6252D especially for MB processing) was supplied by NatureWorks LLC (USA), and the melt flowing rate (MFR) was about $120 \mathrm{~g} / 10 \mathrm{~min}$ at $210^{\circ} \mathrm{C}(2.16 \mathrm{~kg})$. PA11 (grade BMNO TLD) was purchased from Arkema (France), whose MFR was about $30 \mathrm{~g} / 10 \mathrm{~min}$ at $210^{\circ} \mathrm{C}(2.16 \mathrm{~kg})$. Both of these two materials were used as received.

\subsection{Methods}

Processing flow of PLA/PA11 melt blends and MB nonwovens is shown in Figure 1. Both PLA and PA11 pellets were dried 
in a vacuum oven at $80^{\circ} \mathrm{C}$ for $12 \mathrm{~h}$ and then blended by a mechanical mixer at the weight proportion of 95/5, 90/10, $85 / 15,80 / 20$. Then, the mechanical blends were extruded in a twin screw extruder (TSE-30A; Nanjing Ruiya Extrusion System Limited, China; length/diameter $[\mathrm{L} / \mathrm{D}]=40$ ) at $210^{\circ} \mathrm{C}$ and $100 \mathrm{rpm}$.

PLA/PA11 MB nonwovens were manufactured by a laboratoryscale MB nonwoven machine (Jiaxing Longman Measurement and Control Technology Co., Ltd, China) with a single orifice die. The diameter of orifice was $0.3 \mathrm{~mm}$, and the $L / D$ was 40. PLA and PLA/PA11 blends were extruded at $240-250^{\circ} \mathrm{C}$. Nitrogen gas was injected at a fixed pressure of $0.2 \mathrm{MPa}$ to make the melt extruded stably from the orifice. The drawing hot air $(0.3 \mathrm{MPa})$ was also kept at $270-280^{\circ} \mathrm{C}$. The spun MB fibers were cooled at room temperature and collected on a stainless steel roller (collector) with a suction set; the collector speed and the die to collector (DCD) were optimized according to the practical adjustment to get uniform MB nonwovens.

\subsection{Characterization}

Differential scanning calorimetry (DSC) tests were carried out using a Perkin-Elmer DSC 8000 (USA) under $\mathrm{N}_{2}$ atmosphere $(20 \mathrm{~mL} / \mathrm{min})$. Samples of $6 \pm 0.5 \mathrm{mg}$ were weighted and sealed in aluminum crucibles. Samples were heated from $25^{\circ} \mathrm{C}$ to $230^{\circ} \mathrm{C}$ at $10^{\circ} \mathrm{C} / \mathrm{min}$ (first heating), equilibrated at $230^{\circ} \mathrm{C}$ for $3 \mathrm{~min}$ to eliminate the thermal history, cooled to $25^{\circ} \mathrm{C}$ at $10^{\circ} \mathrm{C} /$ min, and then heated again from $25^{\circ} \mathrm{C}$ to $230^{\circ} \mathrm{C}$ at $10^{\circ} \mathrm{C} / \mathrm{min}$ (second heating). The crystal weight fraction $\left(X_{\mathrm{c}}\right)$ of PLA and PA11 was calculated using Equations (1) and (2):

$$
X_{\mathrm{c}}(\mathrm{PLA})=\frac{\Delta H_{\mathrm{m}}(\mathrm{PLA})-\Delta H_{\mathrm{cc}}(\mathrm{PLA})}{\Delta H_{0}(\mathrm{PLA})} \times \frac{100}{W_{\mathrm{t}}}(1)
$$
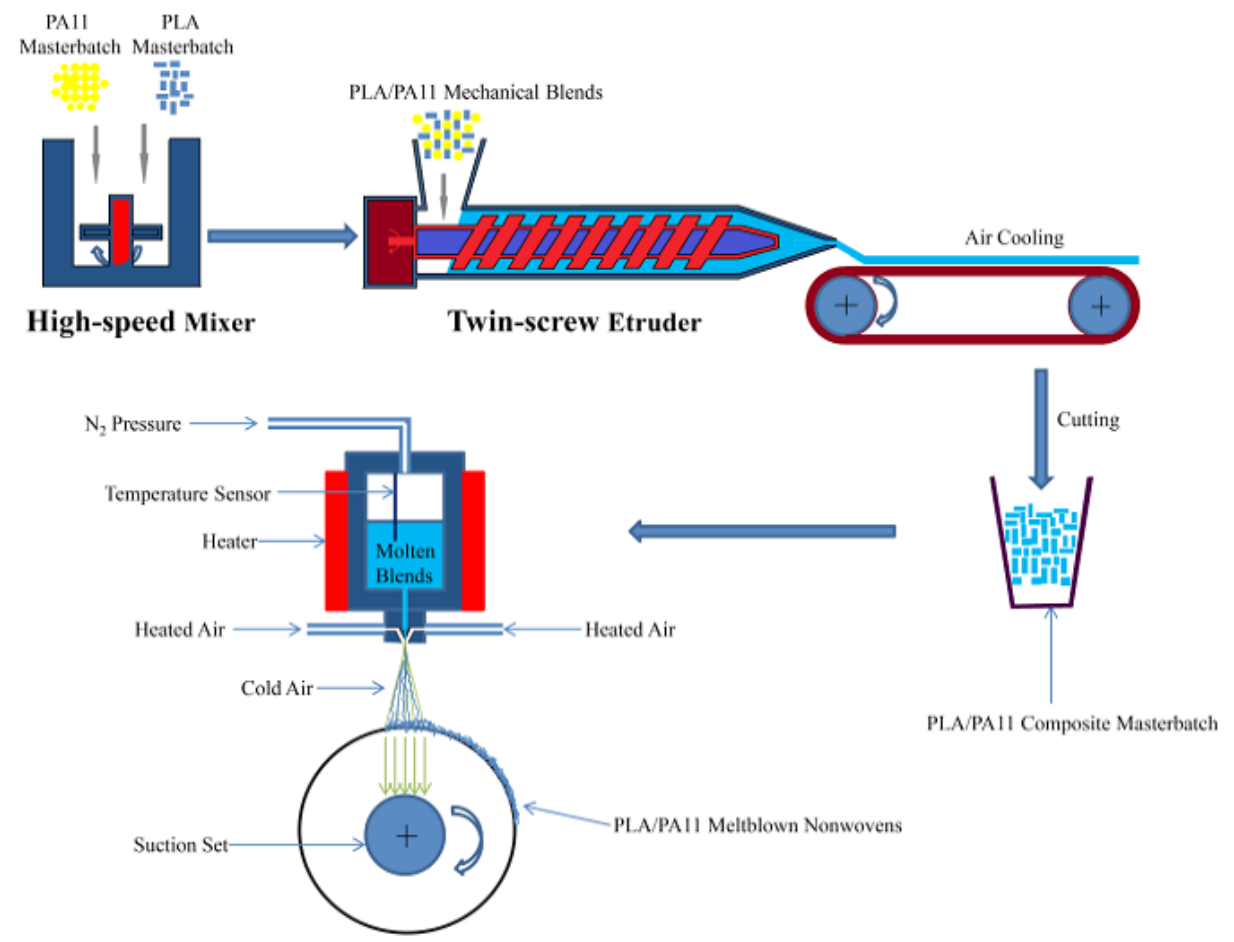

Figure 1. Processing flow of PLA/PA11 melt blends and MB nonwovens Abbreviations: PA11, polyamide 11; PLA, poly (lactic acid); MB, meltblown

$$
X_{\mathrm{c}}(\mathrm{PA} 11)=\frac{\Delta H_{\mathrm{m}}(\mathrm{PA} 11)}{\Delta H_{0}(\mathrm{PA} 11)} \times \frac{100}{W_{\mathrm{t}}}
$$

Here, $\Delta H_{\mathrm{m}}$ is the measured melting enthalpy, $\Delta H_{\mathrm{cc}}$ is the measured cold crystallization enthalpy, $\Delta H_{0}$ is the melting enthalpy for $100 \%$ crystalline PLA (93.1 J/g [18]) and PA11 (189.05 $\mathrm{J} / \mathrm{g}$ [19]), and $W_{\mathrm{t}}$ is the weight fraction in PLA/PA11 blends.

Thermogravimetric analysis (TGA) was performed using a Mettler Toledo TGA/DSC1/1600 (Switzerland) under the $\mathrm{N}_{2}$ atmosphere $(20 \mathrm{~mL} / \mathrm{min})$. Samples of $5 \pm 0.5 \mathrm{mg}$ were weighted and put into a ceramic crucible; samples were heated from room temperature to $550^{\circ} \mathrm{C}$ at $20^{\circ} \mathrm{C} / \mathrm{min}$.

Rheological behaviors were measured using a twin column capillary rheometer (Rosand RH7, UK) with a length-todiameter ratio (L/D) of 16 and the diameter of $1 \mathrm{~mm}$. Test began with two times of pre-compression (pressure $0.3 \mathrm{MPa}$ ) and preheat (a total of $3 \mathrm{~min}$ ) to ensure that the samples were melt and compacted, and the temperatures were set at $210^{\circ} \mathrm{C}$. Shear stress and shear rate were corrected using a zero-length die.

Morphology of MB nonwovens was observed using a fieldemission scanning electron microscopy (FE-SEM; Ultra 55; Carl Zeiss AG, Germany) at an accelerating voltage of 2-3 kV. The MB nonwovens $(1 \mathrm{~cm} \times 1 \mathrm{~cm})$ were gold coated $(2-3 \mathrm{~nm})$ before observation.

Fiber diameters of MB nonwovens were measured using an image analysis software (ImageJ $1.48 \mathrm{v}$; National Institutes of Health, USA) according to the method of Ellison et al. [20]. Five to ten SEM micrographs of each MB nonwovens were taken, and 100 fibers were randomly selected. Statistical data, 
such as average fiber diameter $\left(d_{\mathrm{av}}\right)$, standard deviation (s), and coefficient of variation (CV), were calculated. The fiber diameter distributions were also fit based on polynomial fitting function (polynomial order $=5$ ); $R^{2}$ reflected the goodness of fitting degree.

Mechanical behaviors of PLA and PLA/PA11 MB nonwovens were investigated using a universal tensile machine (Instron-3369, USA) according to the method of ISO 9073-31989. All samples were conditioned under standard laboratory conditions $\left(25 \pm 2^{\circ} \mathrm{C}\right.$ and $\left.65 \% \mathrm{RH}\right)$ for $24 \mathrm{~h}$. Samples with the size of $50 \mathrm{~mm} 20 \mathrm{~mm}$ were selected in rolling direction, and the tensile speed was $50 \mathrm{~mm} / \mathrm{min}$. All the results were calculated as the average of five specimens.

\section{Results and discussion}

\subsection{Melting and crystallization}

DSC second heating and cooling curves of PLA/PA11 blends are shown in Figure 2, and the corresponding thermal parameters are listed in Table 1. In the trace of PLA heating curve, the glass transition temperature $\left(T_{\mathrm{g}}\right)$ was $57.1^{\circ} \mathrm{C}$ and the cold crystallization temperature $\left(T_{\text {cc }}\right)$ at $121.6^{\circ} \mathrm{C}$ was observed due to the mobility and rearrangement of PLA macromolecules. PLA displayed two obvious separated melting peaks $\left(T_{m}\right)$ which could be explained by the mechanisms of melt recrystallization, multiple lamellae, or crystal structures [21]. In the cooling process of PLA, no obvious crystallization peak $\left(T_{c}\right)$ was found because of its slow crystallization rate. In the heating trace of PA11, double $T_{m}$ peaks could also be found, but $T_{\mathrm{g}}$ and $T_{\mathrm{cc}}$ of PA11 were not obvious. PA11 had high $T_{c}\left(165.6^{\circ} \mathrm{C}\right)$, and the sharp and narrow $T_{c}$ peak indicated its fast crystallization rate, because the $\mathrm{N}-\mathrm{H}$ bonds between PA11 macromolecule formed hydrogen bond quickly which was favorable for crystallization. With regard to PLA/PA11 blends, the $T_{\text {cc }}$ was lower than that of PLA, and PLA/PA11 (90/10) displayed the lowest $T_{\text {cc }}\left(116.6^{\circ} \mathrm{C}\right)$. The degree of crystallinity $\left(X_{c}\right)$ of PLA in PLA/PA11 blends was also enhanced from $1.9 \%$ to $5.3 \%$, which were higher than that of PLA, suggesting that PA11 could be acted as a nucleating agent and promoted the crystallization of PLA. By increasing the blending ratio of PA11, both the corresponding melting enthalpy $\left(\Delta_{m}\right)$ and $T_{m}$ peaks of PA11 in PLA/PA11 blends were increased proportionally, but only one single $T_{m}$ peak of PA11 was observed. The $X_{c} s$ of PA11 in PLA/PA11 blends were regularly increased from $16.9 \%$ to $24.6 \%$ with the content of PA11 increased, but all were lower than that of neat PA11 (24.8\%), which demonstrated that the crystallization behavior of PA11 was inhibited by the PLA matrix.

It was further confirmed in the cooling traces of PLA/PA11 blends. It was interesting to find that the crystallization peaks of PA11 at high temperature $\left(165.6^{\circ} \mathrm{C}\right)$ became weak, while those peaks at low temperature $\left(\approx 100^{\circ} \mathrm{C}\right)$ turned into more apparent. This phenomenon was regarded as the typical confined crystallization, and it was common in immiscible polymer blends with dispersed phases, especially in the crystalline/amorphous immiscible polymer blends with "sea-island" structures such as PA6, iPP, LLDPE, and PEO [22-24]. It was also reported that
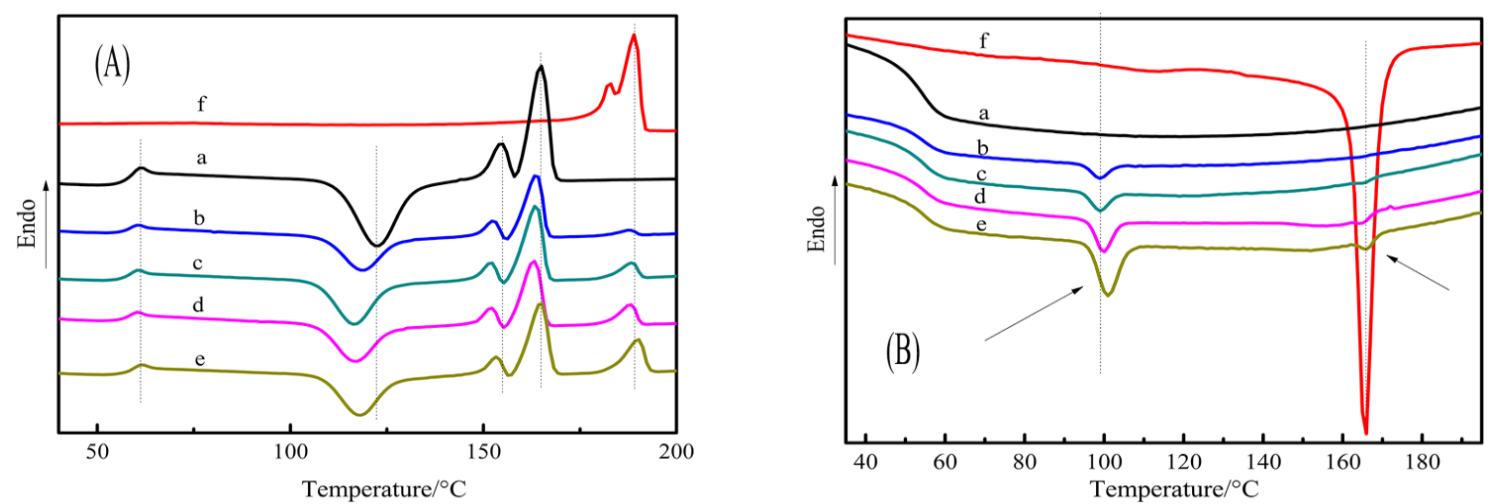

Figure 2. DSC (A) second heating (B) cooling curves of PLA/PA11 blends: (a) 100/0, (b) 95/5, (c) 90/10, (d) 85/15, (e) 80/20, (f) 0/100. Abbreviations: DSC, differential scanning calorimetry; PA11, polyamide 11; PLA, poly (lactic acid)

Table 1. DSC parameters of PLA/PA11 blends

\begin{tabular}{|c|c|c|c|c|c|c|c|}
\hline \multirow{2}{*}{$\begin{array}{l}\text { PLA/PA11 } \\
\text { (wt \%) }\end{array}$} & \multicolumn{4}{|c|}{ Second heating $\left({ }^{\circ} \mathrm{C}\right)$} & \multirow{2}{*}{$\begin{array}{c}\text { Cooling }\left({ }^{\circ} \mathrm{C}\right) \\
T_{c} \text { (PA11) }\end{array}$} & \multicolumn{2}{|c|}{$\begin{array}{c}\text { Degree of crystallinity } \\
(\%)\end{array}$} \\
\hline & $T_{g}(P L A)$ & $T_{c c}(P L A)$ & $T_{m 1}$ (PLA) & $T_{m 2}$ (PA11) & & $X_{c 1}$ (PLA) & $X_{c 2}$ (PA11) \\
\hline $100 / 0$ & 57.1 & 121.6 & $153.9,164.1$ & - & - & 0.1 & - \\
\hline $0 / 100$ & 59.2 & - & - & $181.9,188.4$ & 165.6 & - & 24.8 \\
\hline $95 / 5$ & 57.5 & 118.7 & $152.7,163.7$ & 187.5 & 99.0 & 1.9 & 16.9 \\
\hline $90 / 10$ & 57.2 & 116.6 & $151.9,163.6$ & 188.4 & $99.1,165.5$ & 3.3 & 22.2 \\
\hline $85 / 15$ & 56.7 & 116.7 & $152.2,162.9$ & 188.2 & $99.9,166.2$ & 3.4 & 22.6 \\
\hline $80 / 20$ & 57.7 & 117.7 & $153.4,164.8$ & 190.1 & $100.9,166.2$ & 5.3 & 24.6 \\
\hline
\end{tabular}

Abbreviations: DSC, differential scanning calorimetry; PA11, polyamide 11; PLA, poly (lactic acid) 
PA11, as a dispersed phase, underwent supercooling during the cooling process. The crystallization peak of PA11 at high $T_{c}$ was corresponding to some more perfect crystals with a relative large volume, while that at low $T_{c}$ was corresponding to some unperfect crystals with small size.

\subsection{Thermal stability}

Biodegradable polymers generally displayed poor thermal stability, which affected the processing and properties of end product. Figure 3 shows the weight as a function of temperature for PLA/PA11 blends. A single thermal degradation stage was observed in both PLA and PA11. The initial thermal decomposition temperature $\left(T_{\text {initial }}\right)$ of PLA was about $284.4^{\circ} \mathrm{C}$, and the practical $\mathrm{MB}$ processing temperature was generally $<250^{\circ} \mathrm{C}$. In comparison with PLA, PA11 displayed higher thermal stability with the $T_{\text {initial }}$ of $332.3^{\circ} \mathrm{C}$. The thermal degradation of PLA and PA11 took place via different mechanisms, since two obvious decomposition stages could be observed in PLA/PA11 blends. Both non-free and free radical theories were adopted to explain the thermal degradation of PLA [25-26]. Thermal degradation mechanism of PA11 was similar to PA6, PA66, and PA12, which was due to the cross-linking between the lactam and dehydration process. Blending of $5 \%-20 \%$ PA11 could increase the $T_{\text {initial }}$ of PLA by $12.4-19.9^{\circ} \mathrm{C}$, which indicated that PA11 could efficiently improve the thermal stability of PLA. The possible reason for this phenomenon was that the end groups in PLA, such as $-\mathrm{OH}$ and $-\mathrm{COOH}$ as well as the generated free radicals in the process of thermal decomposition, could be reacted with the amide group in PA11. Hydrogen bonds or polycondensation reaction could also inhibit the thermal degradation of PLA.

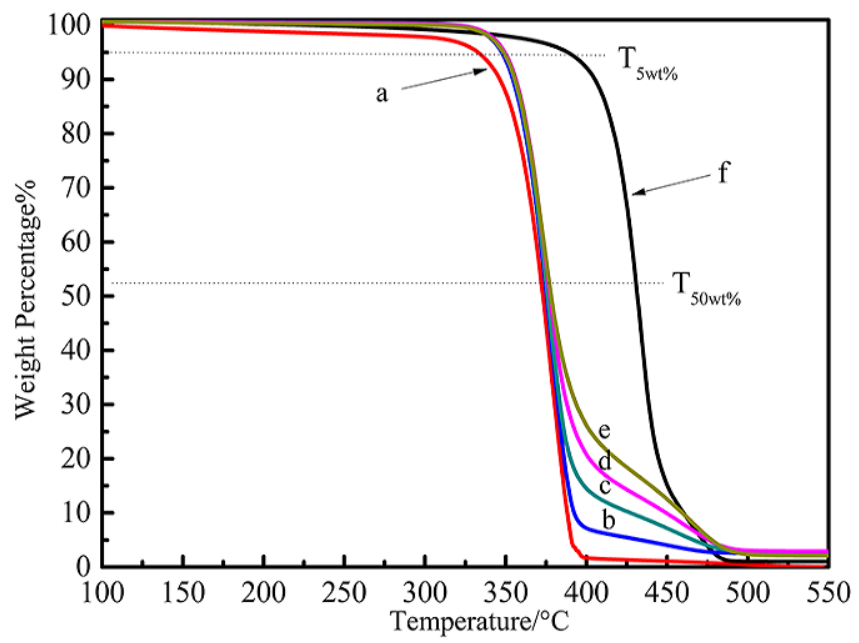

Figure 3. TG curves of PLA/PA11 blends: (a) 100/0, (b) 95/5, (c) 90/10, (d) $85 / 15$, (e) 80/20, (f) 0/100 Abbreviations: PA11, polyamide 11; PLA, poly (lactic acid); TG, thermogravimetric

\subsection{Rheological behaviors}

All the thermoplastic polymers could theoretically be applied to produce MB nonwovens, but the properties of the polymers, especially the melt viscosity, significantly affected the processing of MB technology. The process dynamics and web structure of $\mathrm{MB}$ nonwovens were also influenced by the rheological properties of the melt [27]. The effect of shear rates $(\mathrm{v})$ on the apparent viscosity $\left(\eta_{\mathrm{a}}\right)$ of the PLA/PA11 blends at $210^{\circ} \mathrm{C}$ were is shown in Figure 4 . It was obvious to find that all the PLA/PA11 blends exhibited non-Newtonian "shearthinning" behaviors, and the ( $\eta_{a}$ of the PLA/PA11 decreased significantly with increasing $\gamma$. However, $\eta_{a}$ of melts became stable when $y$ further increased $\left(>3,000 \mathrm{~s}^{-1}\right)$, because most of the entanglement nodes had been removed and the molecular orientation tended to be steady. $\eta_{a}$ of PA11 was larger than that of PLA, but it was also sensitive to the shear rate due to the weakening of intermolecular hydrogen bond interaction and chain entanglement at high temperature. $\left(\eta_{a}\right.$ of PLA/PA11 blends ranged logically between PLA and PA11, and the $\left(\eta_{a}\right.$ increased with blending more amount of PA11. It could be ascribed to the enhanced chain entanglement and generated chain network because of the reaction between PLA and PA11. The overall rheological trends of PLA/PA11 blends were similar to those of neat PLA.

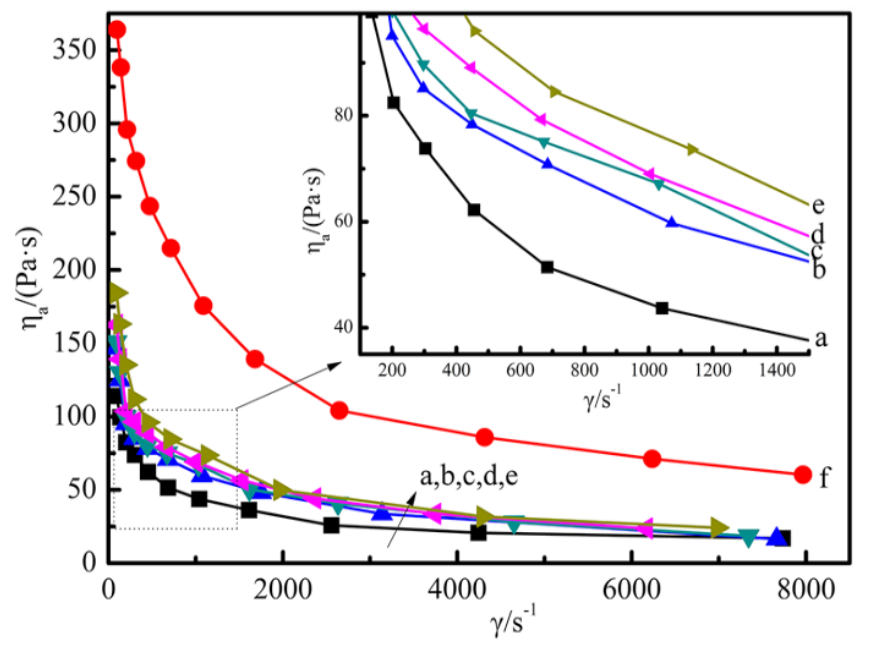

Figure 4. Apparent viscosity $\eta_{a}$ versus shear rate $y$ at $210^{\circ} \mathrm{C}$ of PLA/ PA11 blends: (a) 100/0, (b) 95/5, (c) 90/10, (d) 85/15, (e) 80/20, (f) 0/100 Abbreviations: PA11, polyamide 11; PLA, poly (lactic acid)

\subsection{Morphology and fiber diameter distribution of PLA/ PA11 MB nonwovens}

Figure 5 shows the morphologies and fiber diameter distributions of PLA/PA11 MB nonwovens. It was found that the surface of PLA MB fibers was smooth, whose diameters ranged from $0.5 \mu \mathrm{m}$ to $7 \mu \mathrm{m}$. The turbulent drawing airflow resulted in the irregular drawing force of hot air on the extruded polymer melt; therefore, the diameters of MB fibers were diverse and displayed a normal distribution with the peak at 2-3 $\mu \mathrm{m}$. The average fiber diameter $\left(d_{\text {av }}\right)$ of PLA MB fibers was $3.07 \mu \mathrm{m}$ as a typical MB technology could produce 2-5 $\mu \mathrm{m}$ [1]. By increasing the content of PA11 in PLA/PA11 blends, the $d_{a v}$ of PLA/PA11 $\mathrm{MB}$ nonwovens was also increased, and it could be ascribed to the decrease in MB spinnability in comparison with neat PLA. The extruded PLA/PA11 melt from the die underwent more violent whipping motions and insufficient drawing before reaching the collector. The whipping was believed to contribute to the defects of MB web such as nonuniform fiber diameters, broken fibers, polymer particles, and adhesion between fibers [27]. Tan et al. [28] also found that increasing the melt viscosity led to an increase in fiber diameter of MB nonwovens. Thus, the surface of PLA/PA11 MB fibers became rough, the diameters got nonuniform MB nonwovensalong the fibers' length, and some defects on the web were also found. The results of 

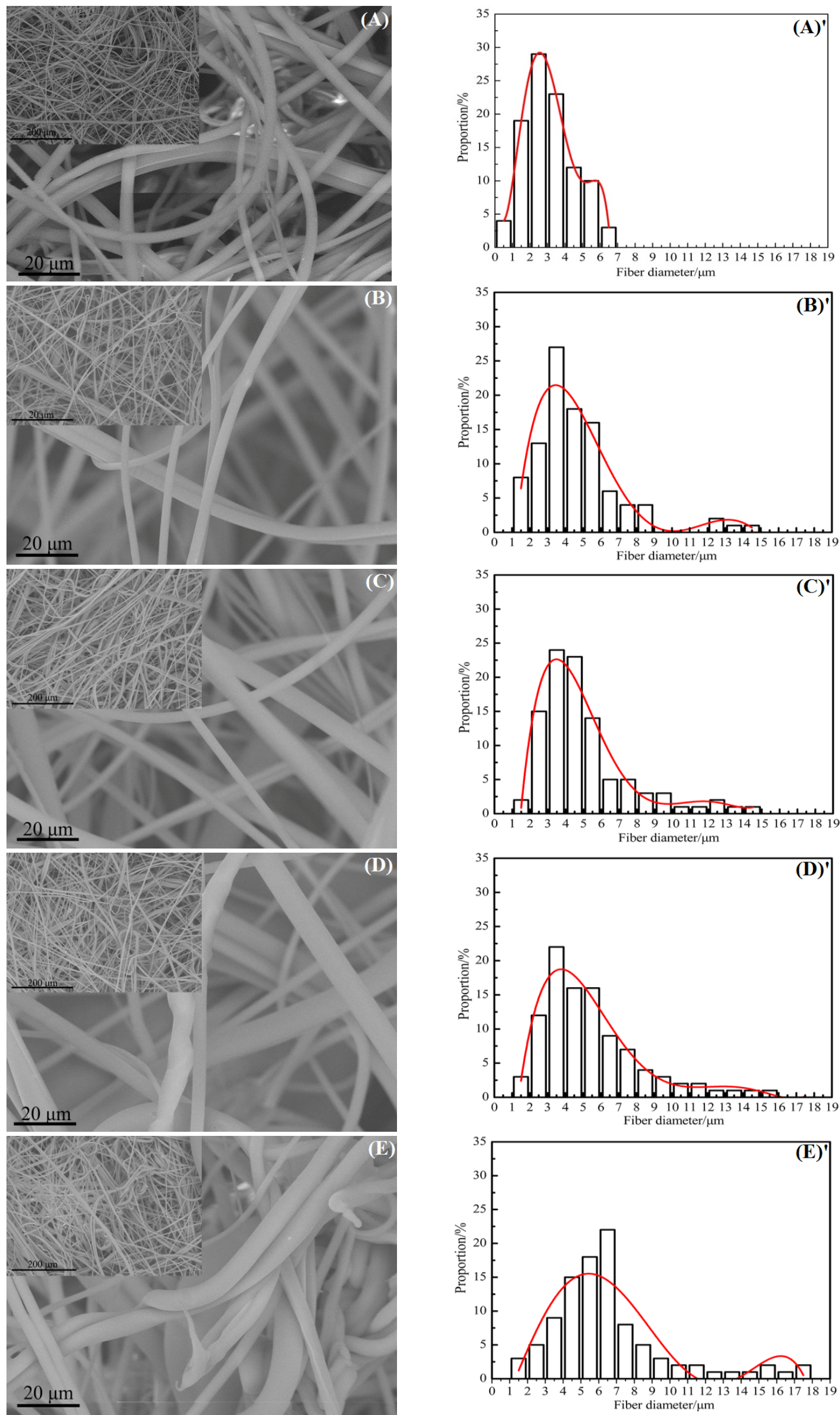

Figure 5. SEM images of PLA/PA11 MB nonwovens: (A) 100/0, (B) 95/5, (C) 90/10, (D) 85/15, (E) 80/20, and the corresponding fiber diameter

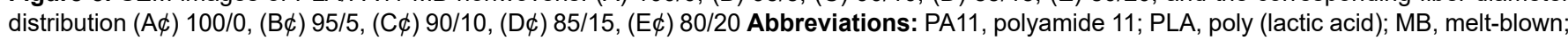
SEM, scanning electron microscopy 
Table 2. Average diameter and diameter distribution parameters of PLA/PA11 MB fibers

\begin{tabular}{|c|c|c|c|c|c|}
\hline (PLA/PA11) (wt\%) & Peak value of distribution $\mathbf{( m m )}$ & dav $(\mathbf{m m})$ & $\mathbf{s}(\mathbf{m m})$ & CV (\%) & R2 (\%) \\
\hline $100 / 0$ & $2-3$ & 3.07 & 1.37 & 44.6 & 99.8 \\
\hline $95 / 5$ & $3-4$ & 4.31 & 1.83 & 42.5 & 80.4 \\
\hline $90 / 10$ & $3-4$ & 5.05 & 2.59 & 51.3 & 92.2 \\
\hline $85 / 15$ & $3-4$ & 5.48 & 2.86 & 52.2 & 94.4 \\
\hline $80 / 20$ & $6-7$ & 6.56 & 3.34 & 50.9 & 71.9 \\
\hline
\end{tabular}

Abbreviations: CV, coefficient of variation; PA11, polyamide 11; PLA, poly (lactic acid); MB, melt-blown

statistical analysis (peak value of distribution, $d_{\mathrm{av}}, s$, and CV) of fiber diameter distribution of PLA/PA11 MB nonwovens are summarized in Table 2. Polynomial fitting functions could well fit into the fiber diameter distribution. The poor miscibility between PLA and PA11 was another nonnegligible factor to increase the fiber distribution, and the defects of PLA/PA11 MB web were further aggravated due to the phase separation, especially when the content of PA11 exceeded $15 \%$.

\subsection{Mechanical properties of PLA/PA11 MB nonwovens}

The tensile mechanical properties of PLA/PA11 MB nonwovens are shown in Figure 6. It is well known that MB nonwovens, with porous and fluffy structures, consist of many superfine fibers and cohesive points, both of which provide the whole mechanical strength. When MB nonwovens undergo stretching, the tensile force first makes the fabric get narrower and the fibers begin to compress each other. At the same time, the tensile force transfers to the adhesive points until these points are disbanded when accumulated to a maximum bearing capacity. An equilibrium stage generally occurs when tensile breakage of fibers and disbandment of adhesive points are balanced with the contribution of new fibers and cohesive points. Finally, the $\mathrm{MB}$ web is destroyed and the strength decreases.

As shown in Figure 6, the elongation of PLA MB nonwovens at maximum strength was $9 \%-10 \%$, the equilibrium stage was short, and the shape of tensile peak was sharp and narrow due to the brittleness of PLA fibers and low adhesive force. The tensile elongation of PLA MB nonwovens could be attributed to the combined effect of porous structure of MB nonwovens and PLA MB fibers, because the breaking elongation of PLA fiber or film was $<5 \%$. However, by increasing the content of PA11 (PA11 content <15\%) in PLA/PA11 blends, the tensile

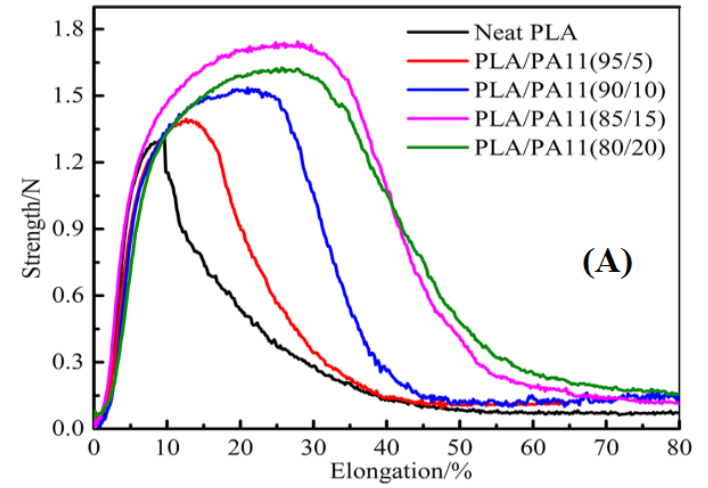

toughness including both the strength and the elongation at maximum strength of PLA/PA11 MB nonwovens was regularly improved. All the PLA/PA11 MB nonwovens presented yield or balanced stages during stretching; in this region, there was competition between the orientation of PLA/PA11 fibers and disbandment of adhesive points. The toughening effect of PA11 on PLA MB nonwovens could be attributed to the great toughness of PA11 and the voids existed in PLA MB fiber. The "rubber-like" PA11 could absorb energy, and the deformation of voids in PLA could increase the toughness of PLA MB fibers [29-30]. More MB fibers would be involved in the stretching process owing to the improvement in toughness; thus, both the strength and elongation were increased. The strength and the elongation at the maximum strength of PLA/ PA11 (85/15) MB nonwovens were increased by $32.5 \%$ and $242.5 \%$ in comparison with those of neat PLA MB nonwovens, which indicated that the PLA/PA11 MB nonwovens could hold strength for a longer time and withstand greater deformation. However, the elongation of PLA/PA11(80/20) MB nonwovens would not increase further and the strength even decreased in comparison with that of PLA/PA11(85/15) MB nonwovens. It was mainly due to the aggravated defects in $\mathrm{MB}$ web including some discontinuous and broken MB fibers which is shown in Figure $9(E)$. A few molten drops also occurred on MB webs, because the phase separation became more apparent which decreased the spinnability of PLA/PA11(80/20) melt.

\section{Conclusion}

A detailed study including melt crystallization thermal and rheological behaviors of PLA/PA11 (95/5, 90/10, 85/15, 80/20) binary bio-based melt blends for MB nonwovens is presented. The corresponding MB nonwovens were also successfully

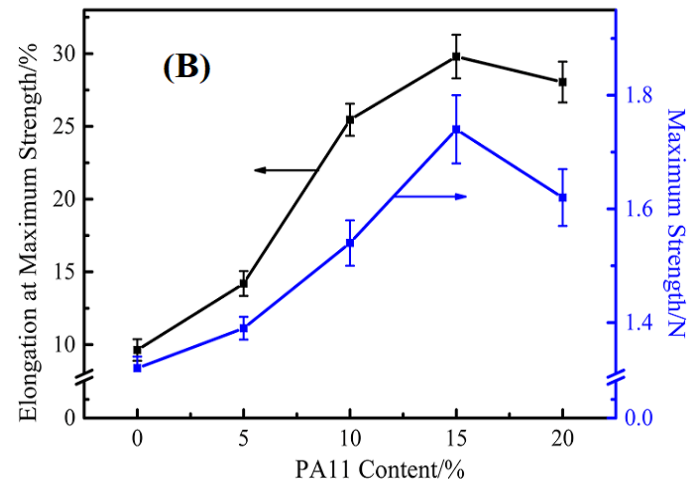

Figure 6. (A) Tensile strength-elongation curves and (B) tensile values of PLA/PA11 MB nonwovensAbbreviations: PA11, polyamide 11; PLA, poly (lactic acid); MB, melt-blown 
manufactured, and the morphology and mechanical properties were investigated. The results of PLA/PA11 melt blends indicated that PA11 formed confined crystals and promoted the cold crystallization of PLA matrix. PA11 could enhance the initial temperatures of thermal degradation of PLA by 12.4 $19.9^{\circ} \mathrm{C}$. Rheological behaviors indicated that all the PLA/PA11 blends exhibited "shear-thinning" behaviors with the apparent viscosity slightly increased in comparison with those of PLA.

As for PLA/PA11 MB nonwovens, morphology and fiber diameter distribution were influenced by the content of PA11, both of which were regularly increased with blended more amount of PA11. The tensile strength and elongation of PLA/ PA11 MB nonwovens were improved, among which the strength and the elongation at the maximum strength of PLA/ PA11 (85/15) MB nonwovens were increased by $32.5 \%$ and $242.5 \%$ in comparison with that of PLA; however, some defects on PLA/PA11 MB webs also occurred when the blending proportion of PA11 increased to $20 \%$.

This environment-friendly toughened PLA/PA11 MB nonwovens were considered to be well applied in the area of disposable filtration, adsorbing, medical, and health care. However, to obtain the PLA/PA11 MB nonwovens with better performance, the miscibility between PLA and PA11 should be further improved using a facile and effective method.

\section{Acknowledgment}

This work was supported by the Key Laboratory of Industrial Textile Materials and Manufacturing Technology of Zhejiang Province.

\section{References}

[1] Bhat, G. (2015). Polymeric nanofibers: recent technology advancements stimulating their growth. Journal of Textile Science \& Engineering, 5(1), 1-3.

[2] Randall, R. B., Wen, C. K. (2003). Fiber formation during melt blowing. International Nonwovens Journal, (2), 21-28.

[3] Hiremath, N., Bhat, G. (2015). Melt blown polymeric nanofibers for medical applications-an overview. Nanoscience \& Technology, 2(1), 1-9.

[4] Liu, Y., Cheng, B., Cheng, G. (2010). Development and filtration performance of polylactic acid meltblowns. Textile Research Journal, 79(9), 771-779.

[5] Pang, X., Zhuang, X., Tang, Z., Chen, X. (2010). Polylactic acid (PLA): research, development and industrialization. Biotechnology Journal, 5(11), 1125-36.

[6] Avinc, O., Khoddami, A. (2009). Overview of Poly(lactic acid) (PLA) fibre: part l: production, properties, performance, environmental impact, and end-use applications of Poly(lactic acid) fibres. Fibre Chemistry, 41(6), 391-401.

[7] Kumar, M., Mohanty, S., Nayak, S. K., Rahail, P. M. (2010). Effect of glycidyl methacrylate (GMA) on the thermal, mechanical and morphological property of biodegradable PLA/PBAT blend and its nanocomposites. Bioresource Technology, 101(21), 8406-8415.
[8] Park, B. S., Song, J. C., Park, D. H., Yoon, K. B. (2012). PLA/chain-extended PEG blends with improved ductility. Journal of Applied Polymer Science, 123(4), 2360-2367.

[9] Yokohara, T., Yamaguchi, M. (2008). Structure and properties for biomass-based polyester blends of PLA and PBS. European Polymer Journal, 44(3), 677-685.

[10] Takayama, T., Todo, M. (2006). Improvement of impact fracture properties of PLA/PCL polymer blend due to $L T I$ addition. Journal of Materials Science, 41(15), 4989-4992.

[11] Hassouna, F., Raquez, J. M., Addiego, F., Toniazzo, V., Ruch, D. (2011). New approach on the development of plasticized polylactide (PLA): grafting of poly(ethylene glycol) (PEG) via reactive extrusion. European Polymer Journal, 47(11), 2134-2144.

[12] Hassouna, F., Raquez, J. M., Addiego, F., Toniazzo, V., Dubios, P. (2012). New development on plasticized poly (lactide): Chemical grafting of citrate on PLA by reactive extrusion. European Polymer Journal, 48(2), 404-415.

[13] Mollova, A., Androsch, R., Mileva, D., Schick, C., Benhamida, A. (2015). Effect of supercooling on crystallization of Polyamide 11. Macromolecules, 46(3), 828-835.

[14] Jacques, B., Werth, M., Merdas, I., Thominette, F., Verdu, J. (2002). Hydrolytic ageing of polyamide 11. 1. Hydrolysis kinetics in water. Polymer, 43(24), 6439-6447.

[15] Dong, W., Cao, X., Li, Y. (2014). High-performance biosourced poly (lactic acid)/polyamide 11 blends with controlled salami structure. Polymer International, 63(6), 1094-1100.

[16] Stoclet, G., Seguela, R., Lefebvre, J. M. (2011). Morphology, thermal behavior and mechanical properties of binary blends of compatible biosourced polymers: polylactide/ polyamide 11. Polymer, 52(6), 1417-1425.

[17] Fatma, W., Lamnawar, K., Maazouz, A., Jaziai, M. (2016), Rheological, morphological and mechanical studies of sustainably sourced polymer blends based on poly(lactic acid) and polyamide 11. Polymers, 8(61), 1-23.

[18] Rashmi, B. J., Prashantha, K., Lacrampe, M. F., Krawczak, P. (2015). Toughening of poly(lactic acid) without sacrificing stiffness and strength by melt-blending with polyamide11 and selective localization of halloysite nanotubes. eXPRESS Polymer Letters, 9(8), 721-735.

[19] Zembouai, I., Kaci, M., Bruzaud, S., Benhamida, A., Corre, Y.M. et al. (2013). A study of morphological, thermal, rheological and barrier properties of Poly (3-hydroxybutyrate-Co-3-Hydroxyvalerate)/polylactide blends prepared by melt mixing. Polymer Testing, 32(5), 842-851.

[20] Ellison, C. J., Phatak, A., Giles, D. W., Macosko, C. W., Bates, F. S.. (2007). Melt blown nanofibers: fiber diameter distributions and onset of fiber breakup. Polymer, 48, 3306-3316.

[21] Pan, P., Kai, W., Zhu, B., Tungalag D., Inoue, Y. (2007). Polymorphous crystallization and multiple melting behavior of Poly(l-lactide): molecular weight dependence. Macromolecules, 40(19), 6898-6905.

[22] Tol, R. T., Mathot, V. B. F., Groeninckx, G. (2005). Confined crystallization phenomena in immiscible polymer blends with dispersed micro-and nanometer sized PA6 droplets, Part 1: uncompatibilized PS/PA6, (PPE/PS)/PA6 and PPE/ PA6 blends. Polymer, 46(2), 369-382. 
[23] Mcnally, T., Mcshane, P., Nally, G. M., Murphy, W. R., Cook, M., et al. (2002). Rheology, phase morphology, mechanical, impact and thermal properties of polypropylene/metallocene catalysed ethylene 1-octene copolymer blends. Polymer, 43(13), 3785-3793.

[24] Abdouss, M., Sanjani, N. S., Azizinejad, F., Shabani, M. (2004). Effects of compatibilization of oxidized polypropylene on PP blends of PP/PA6 and PP/talc. Journal of Applied Polymer Science, 92(5), 2871-2883.

[25] Najafi, N., Heuzeya, M. C., Wood-Adams, P. M. (2012). Control of thermal degradation of polylactide (PLA)clay nanocomposites using chain extenders. Polymer Degradation and Stability, 97(4), 554-565.

[26] Kopinke, F. D., Remmler, M., Mackenzie, K., Milder, M. (1996). Thermal decomposition of biodegradable polyesters- II . Poly (lactic acid). Polymer Degradation and Stability, 52, 329-342.
[27] Leszek, J., Andrzej, Z., Zbigniew, L., Blim, A. (2011). Dynamic of air drawing in the melt blowing of nonwovens from isotactic polypropylene by computer modeling. Journal of Applied Polymer Science, 119(1), 53-65.

[28] Tan, D. H., Zhou, C., Ellison, C. J., Kumar, S., Macokso, C. $W$. (2010). Meltblown fibers: influence of melt viscosity and elasticity on the diameter distribution of meltblown fibers. Journal of Non-Newtonian Fluid Mechanics, 165, 892-900.

[29] Meng, B, Deng, J, Liu, Q, Wu, Z., Yang, W. (2012). Transparent and ductile poly(lactic acid)/poly(butyl acrylate) (PBA) blends: structure and properties. European Polymer Journal, 48(1), 127-135.

[30] Zolali, A. M., Heshmati, V., Favis, B. D. (2016). Ultratough co-continuous PLA/PA11 by interfacially percolated poly(ether-b-amide). Macromolecules, 50(1). 